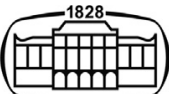

AKADÉMIAI KIADÓ

International Review of Applied Sciences and Engineering

$11(2020) 2,174-180$

Dol:

$10.1556 / 1848.2020 .20048$

(c) 2020 The Authors

\title{
A hybrid method technique for design and optimization of Formula race car exhaust muffler
}

\author{
BARHM MOHAMAD ${ }^{1 *}$, ${ }^{-}$JALICS KAROLY ${ }^{1}$ \\ ANDREI ZELENTSOV ${ }^{2}$ and SALAH AMROUNE ${ }^{3}$ \\ ${ }^{1}$ Faculty of Mechanical Engineering and Informatics, University of Miskolc, Miskolc 3515, Hungary \\ ${ }^{2}$ Piston Engine Department, Bauman Moscow State Technical University, Moscow 105005, Russia \\ ${ }^{3}$ Université Mohamed Boudiaf, B.P 166 ICHBELIA, M'sila, 28000, Algeria
}

Received: September 14, 2019 • Accepted: November 20, 2019

Published online: June 30, 2020

\section{ORIGINAL RESEARCH PAPER}

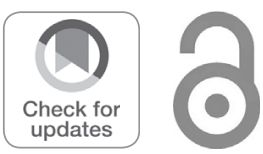

\begin{abstract}
In this work a multilevel Computational Fluid Dynamics (CFD) analysis has been applied for the design of a Formula race car exhaust muffler with improved characteristics of sound pressure level (SPL) and fluid dynamic response. The approaches developed and applied for the optimization process range from the 1D to fully 3D CFD simulation, exploring hybrid approaches based on the integration of a 1D model with 3D tools. Modern mufflers typically have a complex system of chambers and flow paths. There are a variety of sound damping and absorbing mechanisms working to quiet the sound flowing through a muffler and piping system. Two calculation methods were selected for this study. The muffler has a complex inner structure containing perforated pipe and fiber material. Computer-aided design (CAD) file of the muffler was established for developing Finite Element Analysis (FEA) model in AVL BOOST v2017 and another commercial advanced design software (SolidWorks 2017). FEA model was made to monitor the flow properties, pressure and velocity. After the model was verified, sensitivity studies of design parameters were performed to optimize the SPL of the muffler. The software analysis results are included in the paper. Recommendations are made for obtaining smoother SPL curves for various measurement methods.
\end{abstract}

\section{KEYWORDS}

exhaust system, muffler, sound pressure level, finite element analysis, 1D and 3D simulation

\section{INTRODUCTION}

The design of a muffler plays an important role in the overall Noise, vibration and harshness $(\mathrm{NVH})$ performance of a Formula race car. Generally, the control of both the level and quality of formula race car engine parts noise is a key aspect of the design process of a new engine powertrain system, in order to satisfy the legislation limits and provide a characteristic exterior sound [1]. In particular, the gas dynamic noise is radiated from the engine intake and exhaust duct systems due to the highly unsteady flows in the pipes, originated by the periodic cylinder gas exchange process. The insertion loss and the transmission loss of the muffler are used to assess its performance. There are numerous publications available in the acoustic design and the measurement methods of exhaust mufflers. The attenuation of gas dynamic noise relies on suitable reactive and dissipative with hybrid mufflers, designed and optimized to damp or emphasize certain spectral components of the engine noise. Therefore, the design of complex damping systems is a time-consuming operation, which must be carried out by means of concurrent numerical simulations. The objective of this paper is to conduct a sensitivity analysis of Formula Student race car muffler on three key design parameters, i.e. partition (perforated pipe) location, chamber volume variation, and inserting absorbent material in a reactive muffler. Mohamad [2] presented in his technical paper an efficient process to optimize 
the transmission loss of Audi A6 C6 2.0 TDi reactive muffler by using Ffowcs Williams and Hawkings analytical method, and this review depicts velocity, pressure distribution and sound power level along the muffler ducts, the paper reveals that the nonlinear acoustic solver can be applied to model noise generation and transmission from an initial statistically steady turbulent flow also Ffowcs Williams-Hawking (FW$\mathrm{H})$ acoustic analogy. Mohamad and Zelentsov [3] used CFD analysis for the design of an engine intake manifold with improved characteristics of noise reduction and fluid dynamic response. The approaches developed and applied for the optimization process range from the $1 \mathrm{D}$ to fully $3 \mathrm{D}$ CFD simulation by coupling technique method. Mohamad and Amroune [4] explored hybrid approaches based on the integration of a $1 \mathrm{D}$ model and $3 \mathrm{D}$ tools to describe the flow effects on engine exhaust chamber acoustic level, and they showed the transmission loss of muffler at different frequency from the solver. Mohamad et al. [5] study acoustic characterization based on the transfer matrix method (TMM) technique, the result of their study of an existing muffler has been compared with vehicle level test experimental data. The transmission loss has been optimized for new muffler design; other literatures played a significant role in validate their results. Mohamad [6] studied several new techniques through that literature review; the latest development has been done on exhaust systems with regard to acoustic performance. The basic theory behind both approaches is explained as well as a source characterization technique that can be used to link the two methods. Some acoustic software tool has been applied to a variety of exhaust systems.

\section{METHODOLOGY}

\subsection{CAD model}

The geometry was implemented based on current FS reactive muffler prototype using SolidWorks 2017 advanced design software, including inlet, outlet, perforated pipe and chamber. The perforate pipe was placed in the middle of the cylindrical shaped chamber of the muffler. The cross section and the dimensions of muffler are explained in Fig. 1.

\section{ANALYTICAL BACKGROUND}

\subsection{Software setup}

Several procedures were made to perform the modeling using computational fluid dynamics tools and to create the optimum design for a case study using AVL BOOST v 2017 optimization (commercial software). The muffler was made from titanium alloy, so the gas properties were selected directly from both software databases. The boundary conditions considered for the flow acoustic analysis are representative for the exhaust system at several engine speeds. The details are shown in the scheme below (Fig. 2).

The 1D model created in AVL Boost implies a one-dimensional approach to the description of processes in the intake and exhaust systems of the piston engine. The one-dimensional statement of the problem allows estimating the influence of pipe and channels dimensions (diameters, lengths, fillet radii) on the gas flow. The entire cylinder (section) is considered as a single volume in which the processes of intake, compression, combustion, expansion and outlet occur. This volume, unlike the threedimensional approach, is not divided into subdomains (control or finite volumes). The system of equations (energy, continuity, gas state) is written only for one volume that changes with time (in the three-dimensional approach - the system of equations is solved for each control volume) (Tables 1 and 2).

Inlet boundary conditions (BCs) were mass flow and temperature values from measuring points MP 19, 9, 21, 10 (Fig. 3), outlet BC - pressure in MP 10.

In addition, the wall temperature of an external chamber of the muffler was set: $\mathrm{Tw}=573 \mathrm{~K}$, and heat transfer coefficient $\left(\mathrm{h}_{\mathrm{c}}\right)=50 \mathrm{~W} / \mathrm{m}^{2} / \mathrm{K}$.

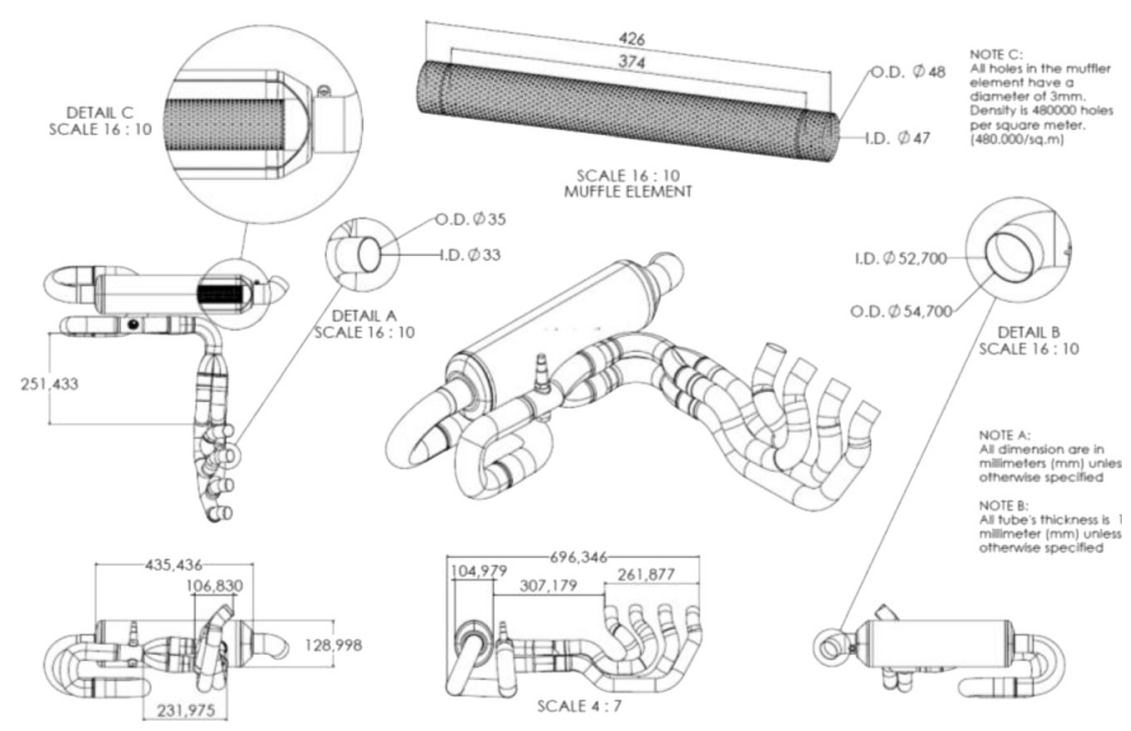

Fig. 1. The cross section and the dimensions of FS muffler 


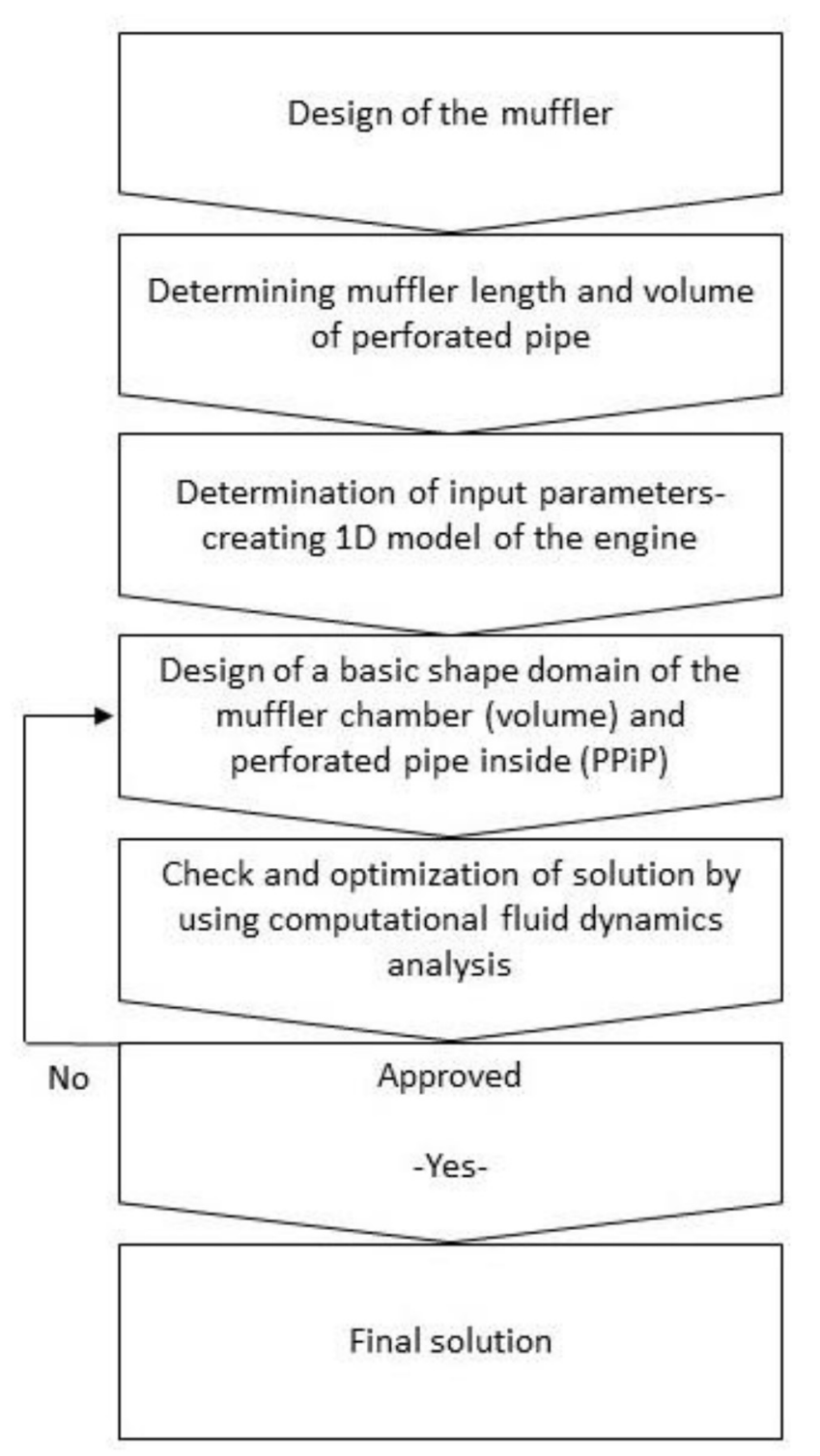

Fig. 2. Flowchart of the design and an optimization process

The initial conditions were the temperature and pressure inside the calculated volume at the initial moment of calculation (the data were taken from the calculation results in Boost).

The pressure drop was defined as the difference between the pressure in the exhaust manifold at the cylinder outlet and the cross section at the outlet of the muffler (computational volume) (Figs 4 and 5).

This paper adopted finite element analysis using SolidWorks 2017 3D flow simulation to calculate product performance and capabilities of the geometric model of the

Table 1. Parameters of perforated pipe

\begin{tabular}{lc}
\hline Porosity & 0.047 \\
Porosity Discharge Coefficient In & 0.6 \\
Porosity Discharge Coefficient Out & 0.6 \\
Perforation-Hole Diameter & $3 \mathrm{~mm}$ \\
Perforation-Wall Thickness & $0.5 \mathrm{~mm}$ \\
\hline
\end{tabular}

Table 2. Model cells properties

\begin{tabular}{lc}
\hline Properties & Cells \\
\hline Basic Mesh Dimensions & $\mathrm{Nx}=82, \mathrm{Ny}=16, \mathrm{Nz}=20$ \\
Fluid cells & 565,554 \\
Solid cells & 259,408 \\
Trimmed cells & 0 \\
Total cells & 824,962 \\
\hline
\end{tabular}

muffler. Its surface mesh was refined to establish the finite element analysis of PPiP muffler. All internal walls are set as real walls with a surface roughness of $0.5 \mu \mathrm{m}$.

\subsection{Mathematical analysis}

The mathematical model is based on the fundamental equations of three-dimensional nonstationary transport: the equations of momentum (Navier-Stokes), energy (FourierKirchhoff) and the conservation of mass (continuity), which take the form of Reynolds after the averaging procedure by the Favre method:

$$
\begin{aligned}
& \bar{\rho} \frac{\mathrm{d} \overline{\mathrm{W}_{\mathrm{i}}}}{\mathrm{dt}}=\overline{\mathrm{G}}_{\mathrm{i}}-\frac{\partial \overline{\mathrm{p}}}{\partial \mathrm{x}_{\mathrm{i}}}+\frac{\partial}{\partial \mathrm{x}_{\mathrm{j}}}\left[\mu\left(\frac{\partial \overline{\mathrm{W}_{\mathrm{i}}}}{\partial \mathrm{x}_{\mathrm{j}}}+\frac{\partial \overline{\mathrm{W}_{\mathrm{j}}}}{\partial \mathrm{x}_{\mathrm{i}}}-\frac{2}{3} \delta_{\mathrm{ij}} \frac{\partial \overline{\mathrm{W}_{\mathrm{k}}}}{\partial \mathrm{x}_{\mathrm{k}}}\right)-\bar{\rho} \overline{\mathrm{W}_{\mathrm{i}}^{\prime} \mathrm{W}_{\mathrm{j}}^{\prime}}\right], \\
& \bar{\rho} \frac{\mathrm{d} \overline{\mathrm{H}}}{\mathrm{dt}}=\mid \overline{\mathrm{G}}_{\mathrm{j}} \overline{\mathrm{W}_{\mathrm{j}}}+\frac{\partial \overline{\mathrm{p}}}{\partial \mathrm{t}}+\frac{\partial}{\partial \mathrm{x}_{\mathrm{i}}}\left(\overline{\tau_{\mathrm{ij}}} \overline{\mathrm{W}_{\mathrm{j}}}\right)+\frac{\partial}{\partial \mathrm{x}_{\mathrm{j}}}\left(\lambda \frac{\partial \overline{\mathrm{T}}}{\partial \mathrm{x}_{\mathrm{j}}}-c_{\mathrm{p}} \bar{\rho} \overline{\mathrm{T}_{\mathrm{j}}}\right), \\
& \frac{\partial \bar{\rho}}{\partial \mathrm{t}}+\frac{\partial}{\partial \mathrm{x}_{\mathrm{j}}}\left(\bar{\rho} \overline{\mathrm{W}_{\mathrm{j}}}\right)=0
\end{aligned}
$$

where $\mathrm{W}_{\mathrm{i}}, \mathrm{W}_{\mathrm{j}}, \mathrm{W}_{\mathrm{k}}$ are the projections of velocity vector, $\mathrm{m} / \mathrm{s}$; $p$ is the pressure, $N / \mathrm{m}^{2} ; \mathrm{G}_{\mathrm{i}}$ is the projection of the density vector of the volume forces $\left(\mathrm{N} / \mathrm{m}^{3}\right)$ onto the $\mathrm{Ox}_{\mathrm{i}}$ axis of a rectangular Cartesian coordinate system; $\mathrm{H}$ is the total specific energy, $\mathrm{J} / \mathrm{kg} ; \mathrm{T}$ is the temperature, $\mathrm{K} ; \mu$ is the

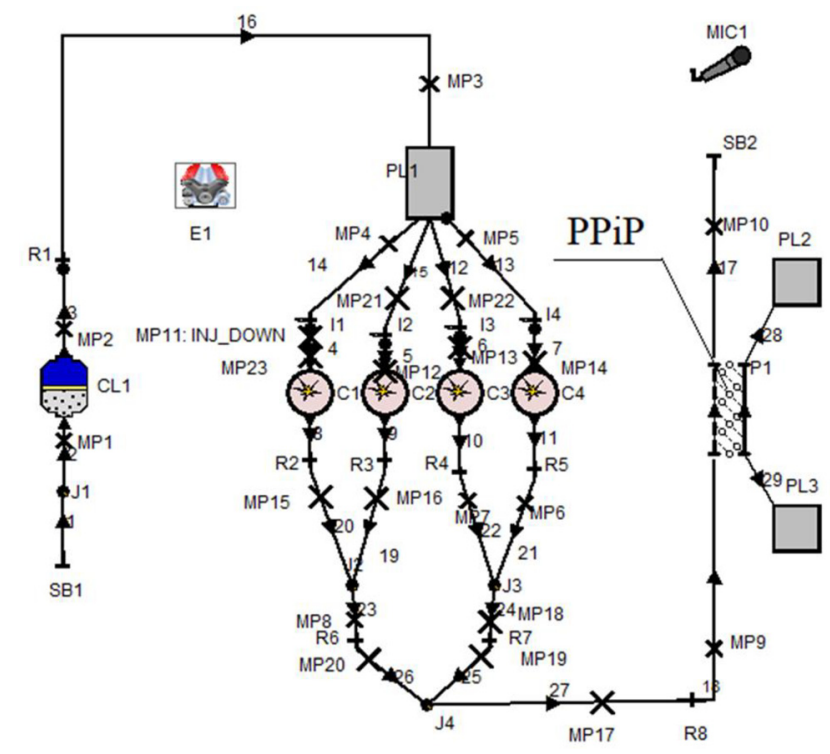

Fig. 3. Scheme of Honda CBR 600RR (PC 37) race car engine with perforated pipe in pipe (PPiP) as part of muffler 


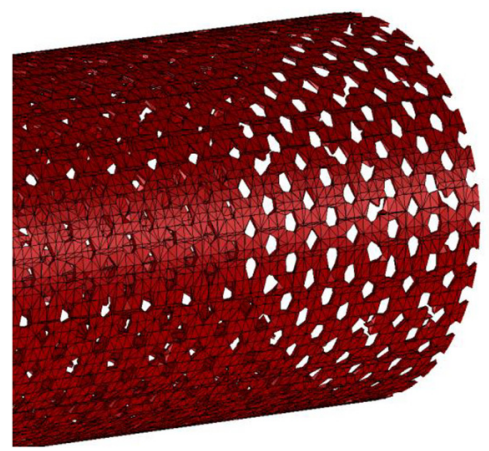

Fig. 4. Refinement mesh of perforated tube

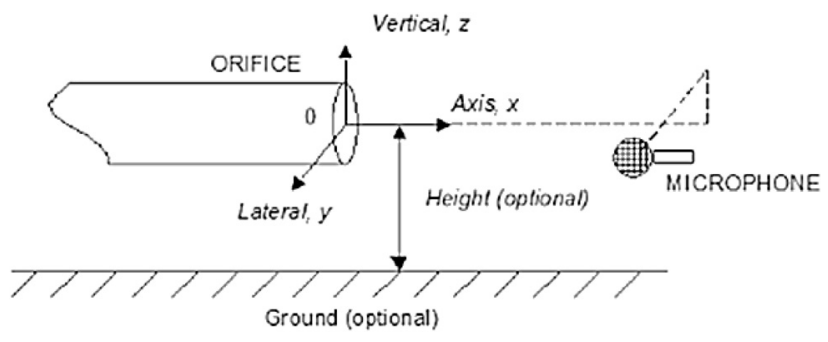

Fig. 5. Position of system boundary relative to the microphone

dynamic viscosity, $\mathrm{kg} /(\mathrm{m} / \mathrm{s}), \bar{\tau}_{\mathrm{ij}}$ is the averaged Reynolds stress for components, $c_{\mathrm{p}}$ is the heat capacity at constant pressure, $\mathrm{J} /$ $(\mathrm{kg} / \mathrm{K}), \lambda$ is the thermal conductivity, $\mathrm{W} /(\mathrm{m} / \mathrm{K}) ; \delta_{\mathrm{ij}}$ is the Kronecker symbol; $\mathrm{t}$ is time value, $\mathrm{s}$; and $\frac{\mathrm{d}}{\mathrm{dt}}$ is the substantial derivative. The equations use the representation of any parameter $\Phi$ (it can be velocity W, pressure p, enthalpy $\mathrm{H}$, etc.) as the sum of its averaged $\bar{\Phi}$ and pulsation $\Phi^{\prime}$ values.

The system of transport equations in the Reynolds form (1) is closed by the $k-\zeta-f$ turbulence model. This model was specially developed and verified for the processes of flow, combustion, and heat transfer in piston engines [7, 8]. $k-\zeta-f$ model has three equations: for the $k$ kinetic energy of turbulence, for the $\varepsilon$ dissipation rate of this energy known from the $\mathrm{k}-\varepsilon$ model of turbulence, and the equations for the normalized velocity scale $\zeta=\bar{W}^{2} / k$ [9].

Hybrid wall functions [10] were used to determine parameters of gas flow and heat transfer into the boundary layer.
References [11-13] emphasized that this mathematical model is typical for CFD calculations of processes in piston engines.

The effect of flow noise generated by turbulence were declared by ref. [14]:

$$
\begin{aligned}
L_{w}= & \eta_{w}+10 \log \left(P_{a m b} 0.0075\right)-17.5 \log T+20 \log D \\
& +45 \log u-26.9
\end{aligned}
$$

where $L_{w}$ is the overall flow generated noise power level radiated $(\mathrm{dB}) ; \eta_{\mathrm{w}}$ is the efficiency factor $(\mathrm{dB}) ; \mathrm{p}_{\mathrm{amb}}$ is the atmospheric pressure $(\mathrm{Pa}) ; \mathrm{D}$ is the diameter of the pipe $(\mathrm{m})$ and $\mathrm{u}$ the gas flow velocity $(\mathrm{m} / \mathrm{s})$.

The formula predicts the noise power level once the value of the efficiency factor is known from experimental measurements for the specific silencing device. This includes the effects of all parts of the system including flow area changes and perforates. The predicted flow noise is across the complete range of frequencies and not at specific frequencies.

For the exhaust muffler of engines, different muffler structures and parameters obviously had different influences on reducing the noise. Due to the complex work process of the muffler, how to theoretically compute and design the inner structure of the muffler has been a topic which was constantly discussed. To show the effect of absorptive material (AM) and porosity of pipe on sound pressure level can be described as equation below:

Material Porosity $=1-($ Packing Density $) /($ Material Density $)$

Material properties resources including density value can be found in software database.

\section{RESULTS}

\subsection{Flow trajectory}

In Fig. 6 the contour of flow field distribution of the muffler system is shown. As can be seen, the largest flow velocity $(52.799 \mathrm{~m} / \mathrm{s})$ was in the connection pipe of PPiP at the outlet of the muffler and the largest pressure of the body muffler $(102,325.35 \mathrm{~Pa})$ was at the inlet, as seen in Fig. 7.

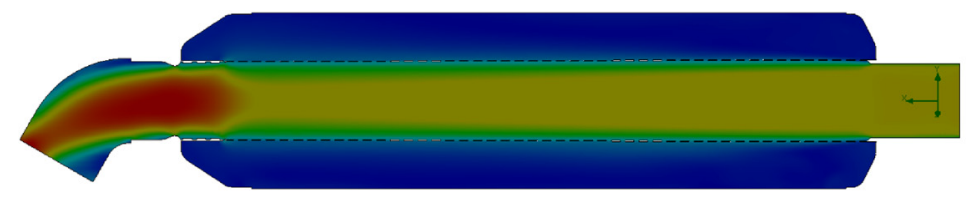

Fig. 6. Velocity distribution start from the right (inlet) and leaves at the left (outlet) in PPiP muffler 


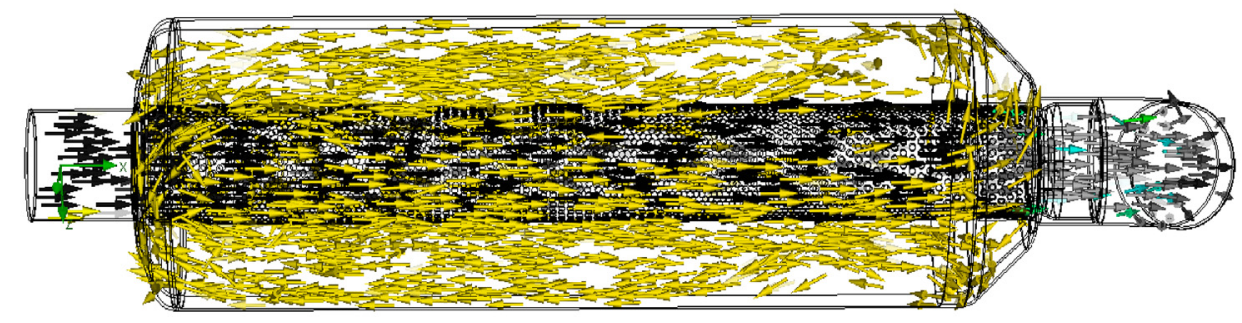

Fig. 7. Pressure contour (Flow trajectories) in perforated tube and the volume part of muffler (The inlet at the left and outlet at the right)

Most of the fluid in the internal of PPiP muffler directly entered into the muffler volume from the perforated pipe. In addition, perforated tube located inside the muffler had holes whose diameter was very small $(3 \mathrm{~mm})$. Due to large resistance, the fluid was greatly reduced when it flowed from holes, details in Fig. 7.

On the basis of three-dimensional calculations, the values of the pressure drop in the simulated muffler were obtained, taking into account the presence of an internal perforated pipe. Also, three-dimensional models allowed to clarify the value of Material Porosity. Further these values were used to calibrate the 1D model of exhaust system in AVL Boost.

\subsection{Power output}

Influence of diameter (Dm_in), diameter of hole of perforated inner pipe (Dm_hole), diameter out of muffler shell (Dm_out) and the length of the muffler variation on Honda engine performance were monitored and optimized based on AVL BOOST solver.

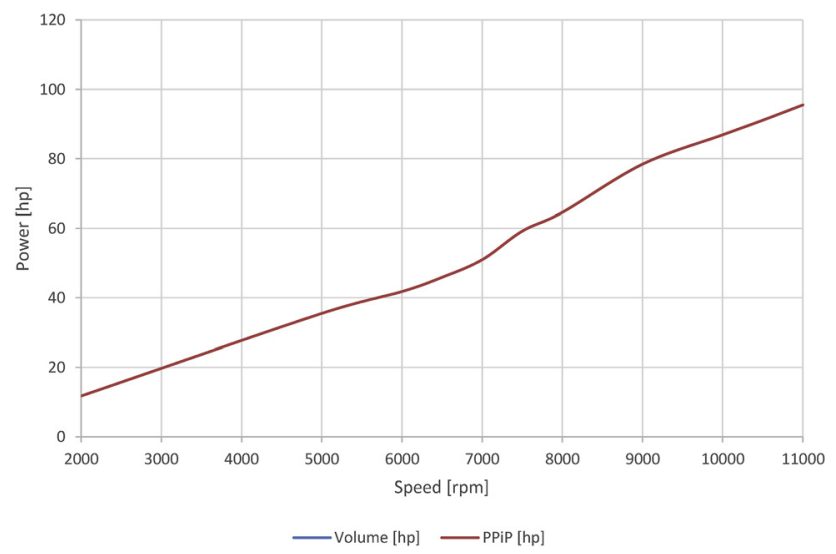

Fig. 8. Comparison of power output for Honda CBR 600RR (PC 37) race car engine with volume and PPiP (Fig. 3)
Using different types of exhaust muffler to current FS engine has no effect on power output, since there is no catalyst convertor or intercooler to create high back pressure (as shown in Fig. 8).

\subsection{Noise level}

As it can be seen from Fig. 9, modified muffler makes it possible to decrease the noise levels but for $n>3,000 \mathrm{rpm}$ noise level is still higher than in case of muffler construction with only volume.

This paper aimed to optimize the average SPL of the muffler instead of taking SPL at all frequencies. This is resulting an increase of SPL with increase of engine speed which may act in frequency domain.

\subsection{The effect of muffler design parameter on noise level}

The effect of geometrical parameters of muffler on its noise reduction performance is studied and reported. Fig. 10

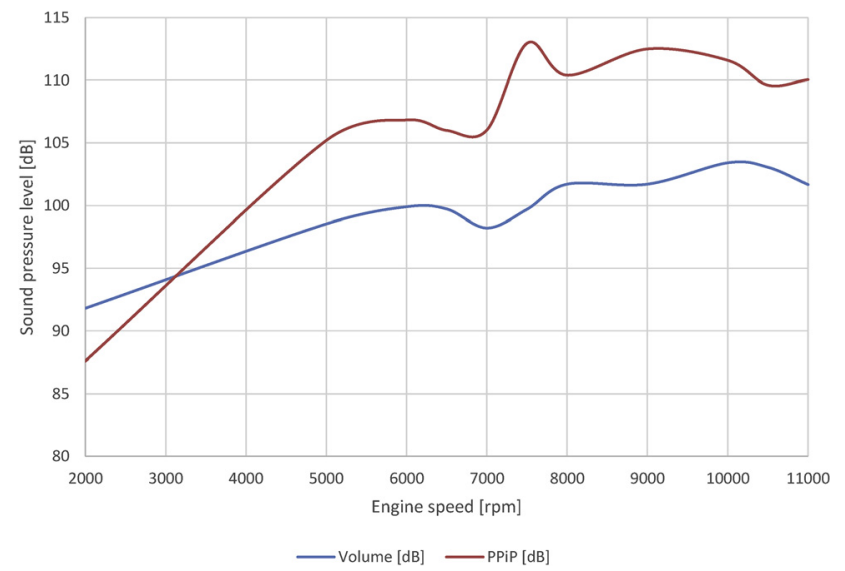

Fig. 9. Comparison of sound pressure level for Honda CBR 600RR (PC 37) race car engine muffler with volume and PPiP (Fig. 3) 


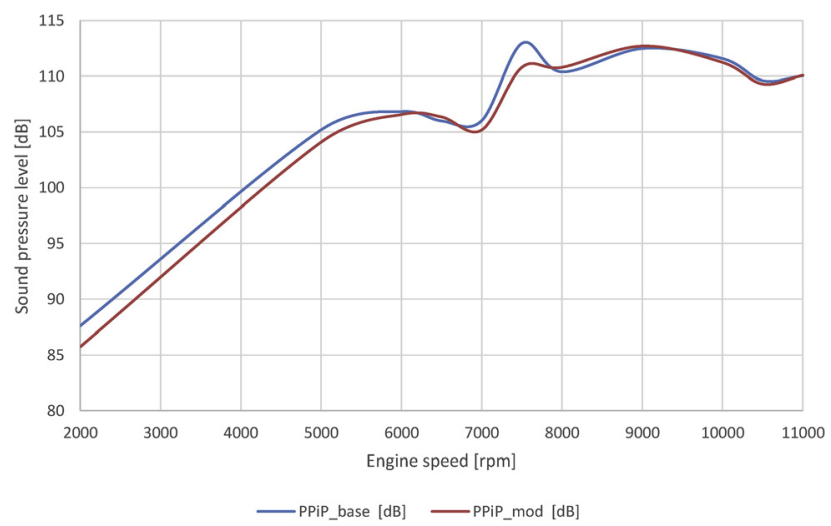

Fig. 10. Honda engine acoustic performance in case of base $\left(D \mathrm{~m} \_\right.$hole $=3 \mathrm{~mm}, \mathrm{Dm} \_$in $=47 \mathrm{~mm}, \mathrm{Dm} \_$out $=116 \mathrm{~mm}$, $\mathrm{Lm}=426 \mathrm{~mm}$ ) and modified (Dm_hole $=3 \mathrm{~mm}$,

Dm_in $=47 \mathrm{~mm}$, Dm_out $=126 \mathrm{~mm}, \mathrm{Lm}=436 \mathrm{~mm}$ ) geometry of muffler with perforated pipe in pipe

shows a comparison of noise levels from the engine at a distance of $1 \mathrm{~m}$ from the muffler cut-off in the case of using base and modified muffler. The simulation of flow noise propagates for base muffler and the discussion of their influencing factors, the effectiveness of this combination theory in the field of flow noise in exhaust gas could reflect the practical condition because the exciting source applied by automobile engine to the muffler was sound pressure rather than vibration velocity when the muffler was connected with automobile engine.

A significant dependence of the engine operation parameters, including the noise level, on the outlet pipe length is determined by the propagation of backward waves from the open end of the pipe. As a result, the lowest noise level while maintaining the power performance of the engine was achieved when Dm_out $=126 \mathrm{~mm}$ and $\mathrm{Lm}=436 \mathrm{~mm}$ (Fig. 11).

From Fig. 12 it can be seen that the use of soundabsorbing material allowed reducing the SPL by $15-20 \%$ in the entire engine speed range. At the same time, the output flow resistance increases, thereby reducing the effective

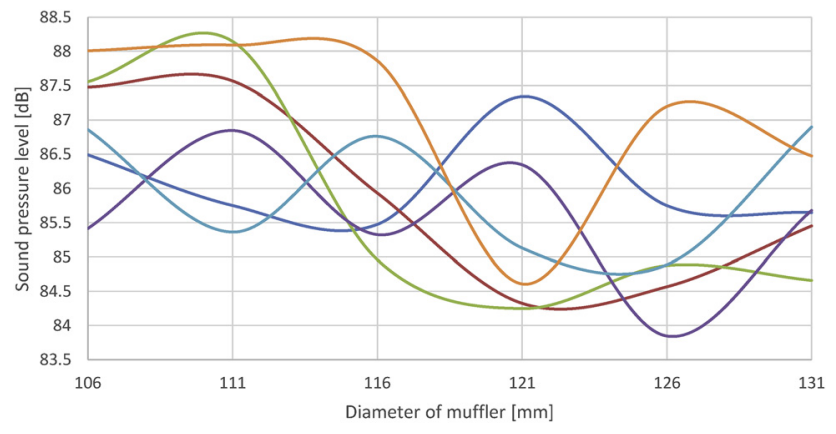

$-\mathrm{Lm}=426[\mathrm{~mm}] \longrightarrow \mathrm{Lm}=416[\mathrm{~mm}]-\mathrm{Lm}=406[\mathrm{~mm}$ $\longrightarrow \mathrm{Lm}=436[\mathrm{~mm}] \longrightarrow \mathrm{Lm}=446[\mathrm{~mm}] \longrightarrow \mathrm{Lm}=456[\mathrm{~mm}]$

Fig. 11. Results of variation of pipe length $(\mathrm{Lm})$ and diameter (Dm_out) of non-perforated outer pipe (diameter of perforated inner pipe Dm_in $=47 \mathrm{~mm}, \mathrm{n}=2000 \mathrm{rpm}$ )

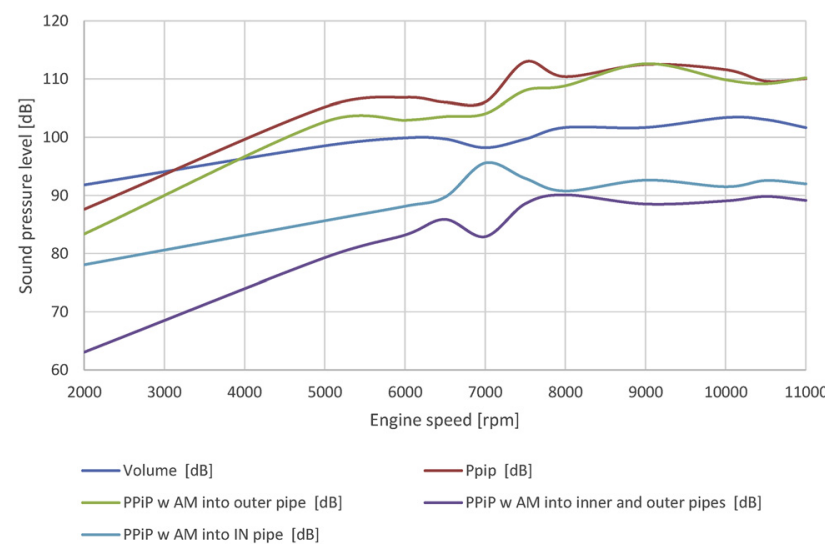

Fig. 12. FS engine sound pressure level with different types of muffler materials

performance of the engine. In addition, during the operation of engine, the sound-absorbing material may be clogged with soot particles present in the exhaust gases, which leads to a further increase in resistance at the outlet and a deterioration in the operating conditions of the engine. The combustion process was simulated in the engine cylinders. In the applied model, it is also possible to simulate the formation of soot, but for SI engine with external mixing the emissions of soot can be neglected. Into the exhaust system the processes of afterburning are not simulated, and the change in the temperature of exhaust gases results from heat exchange with the environment. A main muffler not only had a lighter mass, but also needed to ensure the minimum SPL at the outlet end, which was a multi-objective optimization problem. All optimization processes were carried out on the commercial software.

The use of sound-absorbing material provides a significantly greater reduction in the engine noise level at a comparable size of the muffler.

The parameters of AM: porosity $=0.9$ and flow resistivity $=10,000 \mathrm{~N} \cdot \mathrm{s} / \mathrm{m}^{4}$. The material porosity represents the fraction of air space within the material $(0-1)$. In our case, a Material Porosity of 0.9 defines that $10 \%$ of the volume is filled with material and $90 \%$ is space for the gases.

\section{CONCLUSION}

The acoustics problem is then solved by using an AM, which is a possible step in further decreasing of noise level. The results of using AM into inner pipe first, then to outer pipe and into both inside the muffler at the same time are given in Fig. 12. Exhaust muffler could meet the requirements of exhaust noises, the larger SPL at perforated pipe (PPiP) region was mainly caused by air flow regeneration. The muffler mainly reduced the noise through the transformation of airflow into heat energy in a closed space. The use of $1 \mathrm{D}$ and $3 \mathrm{D}$ simulation of processes in the exhaust system can significantly reduce the time and cost of selecting the optimal size of muffler and exhaust pipes. 
In our case, the results showed great chance for Formula Racing Miskolc team to select correct dimensions, geometry and absorbing material of the muffler for formula race car.

\section{REFERENCES}

[1] J. Cherng, W. Wu, P. Ding, M. Hebbes, and H. Zhang, Design Optimization of Vehicle Muffler Transmission Loss using Hybrid Method. SAE Technical Paper 2015-01-2306, 2015, http:/doi.org/10.4271/201501-2306.

[2] B. Mohamad, "Design and optimization of vehicle muffler using the Ffowcs Williams and Hawkings model," Mach. Des., vol. 11, no. 3, pp. 101-6, 2019.

[3] B. Mohamad and A. Zelentsov, "1D and 3D modeling of modern automotive exhaust manifold," J. Serb. Soc. Comput. Mech., vol. 13, no. 1, pp. 80-91, 2019.

[4] B. Mohamad and S. Amroune, "The analysis and effects of flow acoustic in a commercial automotive exhaust system," in Advances and Trends in Engineering Sciences and Technologies III, Proceedings of the 3rd International Conference on Engineering Sciences and Technologies (ESaT 2018), September 12-14, 2018, High Tatras Mountains, Tatranské Matliare, Slovak Republic, pp. 197-202, 2019.

[5] B. Mohamad, J. Karoly, and M. Kermani, "Exhaust system muffler volume optimization of light commercial passenger car using transfer matrix method," Int. J. Eng. Manag. Sci. (IJEMS), vol. 4, pp. 132-9, 2019.

[6] B. Mohamad, "A review of flow acoustic effects on a commercial automotive exhaust system," Mobil. Veh. Mecha., vol. 45, no. 2, pp. 1-4, 2019b.

[7] R. Tatschl, J. Schneider, D. Basara, A. Brohmer, A. Mehring, and K. Hanjalic, "Progress in the 3D-CFD calculation of the gas and water side heat transfer in engines", in 10. Tagung der Arbeitsprozess des Verbrennungsmotors (Proc. 10th Meeting on the Working Process of the Internal Combustion Engine), Graz, Austria, 2005.

[8] R. Tatschl, B. Basara, J. Schneider, K. Hanjalic, M. Popovac, A. Brohmer, et al., "Advanced turbulent heat transfer modeling for IC-engine applications using AVL FIRE," in Proceedings of International Multidimensional Engine Modeling User's Group Meeting. Detroit, USA, 2006.

[9] M. Hanjalić, M. Popovać, and M. Hadziabdić, "A robust near-wall elliptic-relaxation eddy-viscosity turbulence model for CFD," Int. J. Heat Fluid Flow, vol. 25, pp. 897-901, 2004.

[10] M. Popovać and K. Hanjalić, "Compound wall treatment for RANS computation of complex turbulent flow," in Proc. 3rd M.I.T. Conference, Boston, USA, 2005.

[11] G. Merker, C. Schwarz, and R. Teichmann, Grundlagen Verbrennungsmotoren: Funktionsweise, Simulation, Messtechnik (Fundamentals of Internal Combustion Engines: Mode of Operation, Simulation, Measurement Technology), 9th ed. Wiesbaden: Springer, 2019, p. 1117.

[12] R. Basshuysen and F. Schäfer, (Hrsg.) Handbuch Verbrennungsmotor. 4. Auflage. Wiesbaden: Vieweg und Sohn Verlag, 2007, p. 1032.

[13] R. Z. Kavtaradze, D. O. Onishchenko, A. A. Zelentsov, and S. S. Sergeev, "The influence of rotational charge motion intensity on nitric oxide formation in gas-engine cylinder", Int. J. Heat Mass Tran., vol. 2009, no. 52, pp. 4308-16, 2009, http:/doi.org/10.1016/ j.ijheatmasstransfer.2009.03.060.

[14] A. J. Green and P. N. Smith, "Gas flow noise and pressure loss in heavy vehicle exhaust systems," in Part 1: Experimental Programme. Part 2: Design Data. Institution of Mechanical Engineers, p. 112, ISBN: 0266-7045, 1988. 